\title{
Influências pluviométricas no mapeamento das características da paisagem de um sítio arqueológico com a aplicação de métodos geofísicos e geoestatísticos
}

\author{
Rainfall influences in mapping landscape features of an archaeological \\ site with the application of geophysical and geostatistical methods
}

\author{
Jéssica Lisboa de Albuquerque'(D), Helyelson Paredes Moura"1(i), \\ Joaquim Carlos Barbosa Queiroz ${ }^{1(\mathbb{D}}$, Aline Maria Meiguins de Lima ${ }^{1(1)}$ \\ ' Universidade Federal do Pará, Instituto de Geociências, Belém, PA, Brasil \\ "Universidade Federal do Amapá, Pró-Reitoria de Graduação, Macapá, AP,Brasil
}

\section{RESUMO}

Os estudos arqueológicos têm importância para a compreensão da histórica dos ambientes passados e análise das consequências das mudanças destes no período atual, sendo os métodos geofísicos uma ferramenta importante por permitir uma análise de baixo impacto sobre estes. Este trabalho avaliou a influência da precipitação pluviométrica no mapeamento das características da paisagem do sítio arqueológico AP-MA-05 utilizando métodos geofísicos e geoestatísticos. Para a obtenção dos dados foi utilizado o método geofísico da eletrorresistividade em uma área da UNIFAP de $10 \times 20$ metros. Os dados de precipitação foram coletados na estação do INMET de Macapá. A análise dos dados foi feita com uso de métodos estatísticos e geoestatísticos. Em épocas chuvosa a resistividade do solo apresentou um valor mínimo de 198,7 ohm.m e valor máximo de até 3946 ohm.m, com média de 1188,87ohm.m. Na estação menos chuvosa os valores observados foram de 394 ohm.m (mínimo) e 5863 ohm.m (máximo), com média de 2078,31 ohm.m. Isso demonstra a influência da precipitação pluviométrica na resistividade elétrica aparente, visto que quanto mais intensas foram as chuvas que ocorreram na época da obtenção dos dados, menores foram os valores da resistividade elétrica. A melhor associação entre o método de investigação, o período de levantamento com base nos aspectos climáticos e a aplicação de métodos geoestatísticos facilitou a caracterização do sítio como suporte futuro para sua prospecção.

Palavras-chave: Resistividade elétrica aparente; Perfil do solo; Macapá

\section{ABSTRACT}

Archaeological studies are important for understanding the historical environments and analysis of the consequences of their changes in the current period, and geophysical methods are an important tool for enabling a low-impact analysis on these. This study evaluated the influence of rainfall in mapping of landscape features of the archaeological site AP-MA-05 using geophysical and geostatistical methods. To obtain the data, the geophysical method of electroresistivity was used in an area of UNIFAP of $10 \times 20$ meters. The rainfall data were collected in INMET station in Macapá. Data analysis was performed with use 
of statistical and geostatistical methods. In rainy season, soil resistivity presented a minimum of 198.7 ohm.m and maximum values of up to $3946 \mathrm{ohm} . \mathrm{m}$, with an average of $1188.87 \mathrm{ohm} . \mathrm{m}$. In the less rainy season the observed values were 394 ohm.m (minimum) and 5863 ohm.m (maximum), with an averaging of $2078.31 \mathrm{ohm} . \mathrm{m}$. This demonstrates the influence of rainfall on apparent resistivity, since the more intense the rains that occurred at the time of data were obtained, the lower the values of electrical resistivity. The best association between the research method, the survey period based on climate aspects and the application of geostatistical methods facilitated the characterization of the site as a future support for its prospection.

Keywords: Apparent electrical resistivity; Soil profile; Macapá

\section{INTRODUÇÃO}

O patrimônio arqueológico representa um fator histórico e cultural que tem entrado em conflito com as alterações da paisagem em função do antropismo e da dinâmica natural do ambiente (sujeita a ação dos eventos extremos climáticos, principalmente de chuva), demandando por investimentos tecnológicos que melhor delimitem e protejam estes espaços. Honorato (2009) e Fagundes e Piuzana (2010) apresentam o uso do conceito de paisagem em pesquisas arqueológicas onde não se considera apenas os artefatos arqueológicos encontrados nos sítios, mas também todo um contexto ambiental, onde o meio passa a refletir a história e evolução do ambiente em que se encontra.

Funari (2003) destaca a integração entre os estudos arqueológicos e a investigação das transformações na paisagem de um determinado lugar, ligadas diretamente as ações humanas. Morais (2007) ao apresentar o conceito de paisagem associado ao patrimônio arqueológico, reúne as dimensões relativas à matriz ambiental natural, (relacionada com o meio físico-biótico), e o ambiente modificado, (relacionado com o meio socioeconômico e cultural). Além disso, a urbanização vem cada vez mais suprimindo as áreas arqueológicas, e cada interferência é considerada uma intervenção radical e potencialmente danosa. Logo, a preservação do patrimônio arqueológico no contexto urbano é um processo de mudança de comportamento da sociedade (SILVA; ALMEIDA, 2011).

O sítio arqueológico pode ser admitido como um local onde se encontram vestígios inter-relacionados e que indicariam atividade humanas especificas, como habitação, túmulos, moradias, enterramento, obtenção de materiais e relacionados 
ao culto religioso (FUNARI; NOELLI, 2002). Para Silva e Almeida (2011) a noção de patrimônio arqueológico aborda múltiplas dimensões, portanto quando a sociedade reconhece em dado território sua história e sua vida passa a dar importância e a contribuir para sua preservação/conservação, pois o indivíduo se sente parte desse patrimônio e passa a the atribuir valor. O processo de uso e ocupação do território pode comprometer a preservação desses locais, especialmente na execução de grandes projetos de infraestrutura (MORAES, 2007); uma forma de redução de impactos é o uso de geotecnologias pode proporcionar uma forma de reconstituição do modo de ocupação do território, proporcionando uma nova visão do passado e consequentemente estimulando os sentimentos de pertencimentos, apropriação e preservação do patrimônio arqueológico as diversas histórias (HONORATO, 2009; LIMA, 2009).

Bonnie (2011) e Clue (2011) destacam os benefícios do uso de técnicas apropriadas, que visem o menor comprometimento do ambiente explorado. Moura et al. (2009) exemplifica o emprego de métodos de investigação de subsuperfície (geofísicos - resistividade elétrica) que indiquem a disposição de diferentes materiais antes do processo de escavação. De forma complementar, Vieira (2013) apresenta a aplicação de modelos baseados em métodos geoestatísticos no sentido de aumentar a precisão das estimativas e redução das incertezas, visando minimização dos impactos ambientais.

O emprego de métodos que possibilitem entender as condições gerais da dinâmica da paisagem, contribuindo para o desenvolvimento de prognósticos e interpretações geoambientais, dependem de vários fatores que condicionam sua aplicação e resultados (COELHO; FERREIRA, 2011), dentre estes o conhecimento das variáveis climáticas. Brito-Schimmel et al. (2002) afirmam que no Brasil um dos marcos na aplicação de métodos geofísicos em arqueologia ocorreu nos anos 80, com o emprego de métodos elétricos e magnéticos no mapeamento de sítios de cultura cerâmica na Ilha de Marajó. 
Segundo Gandolfo e Gallas (2005), as menores resistividades elétricas podem ser explicadas como consequência de intensas chuvas que ocorreram na época em que foi realizada a aquisição dos dados. Gandolfo e Gallas (2007) afirmam que a eficácia de um levantamento está condicionada à existência de contrastes dos valores absolutos medidos, sendo dependentes das propriedades físicas do meio investigado ( $\mathrm{pH}$, características do solo) e das condições que interferem no ambiente local (como a intensidade da precipitação pluviométrica).

Desse modo, o papel da precipitação no mapeamento do solo é imprescindível, pois dependendo em que época ocorre a execução do mapeamento o resultado poderá ou não ser aceitável, visto que a precipitação é uma variável ambiental de muita influência em métodos geoelétricos. Vários autores comprovam essa influência, como Cavalcante (2013) em que evidencia alta permeabilidade dos solos da região em meses de alta precipitação, interferindo nos métodos geoelétricos no delineamento de contaminação de aterros; a existência de anomalias de baixa resistividade, em que os ensaios de campos foram realizados em períodos de alta precipitação pluviométrica, em que a infiltração de água no solo é alta (COSTA; MALAGUTTI FILHO, 2008); e na resistividade elétrica aparente, que houve menores valores de resistividade pela consequência de intensas chuvas que ocorreram na época realizada a aquisição dos dados (GANDOLFO; GALLAS, 2005).

O correto mapeamento e reconhecimento destas áreas de relevante importância histórica e ambiental estimulam a identificação social e os valores simbólicos na relação de interação entre os componentes da paisagem. Silva e Almeida (2011) afirmam que a valoração do patrimônio cultural atua como uma fonte primária de conhecimento e enriquecimento individual e coletivo. Desta forma, busca-se avaliar a influência da precipitação pluviométrica no processo de mapeamento das características da paisagem de sítios arqueológicos, por meio de métodos geofísicos e geoestatísticos, visando a melhor caracterização desses bens culturais nas áreas onde estes estão localizados, entendendo estes espaços como áreas destinadas a preservação ou conservação socioambiental. 


\section{MATERIAL E MÉTODOS}

\section{1 Área de estudo}

A área de estudo está localizada no sítio arqueológico AP-MA-05 (0001'S 51은 W), no bairro Universitário, na região sul da cidade de Macapá (AP), no terreno ocupado pela Universidade Federal do Amapá (UNIFAP), abrangendo cerca de 200 m² (Figura 1).

Figura 1 - Mapa de localização da área de estudo

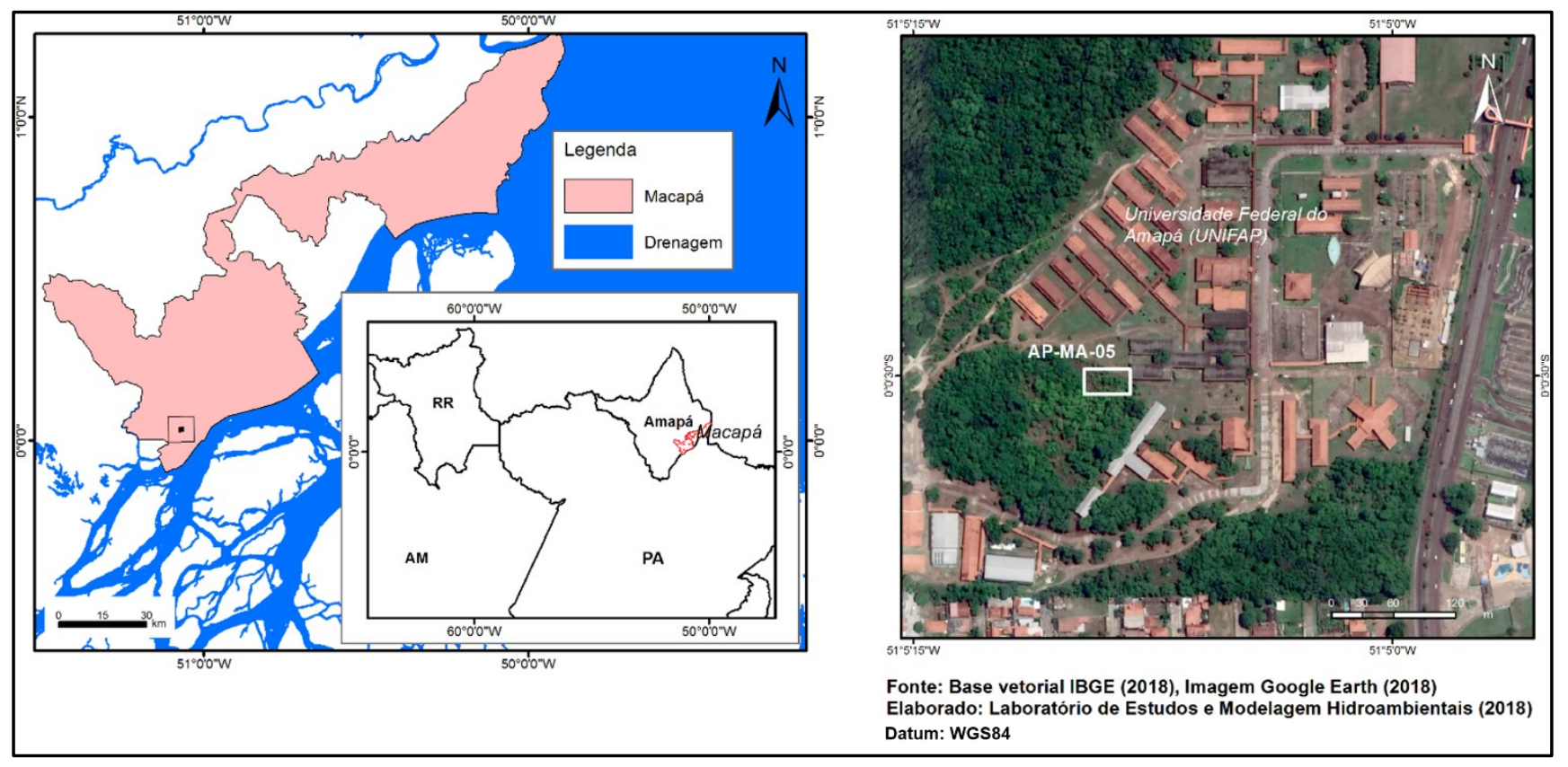

Sítio Arqueológico AP-MA-05 é de origem indígena e foi descoberto em março de 1997 a partir da abertura de uma trincheira para a locação de canos de rede de drenagem de água do Campus Universitário. A escavação foi de $1 \mathrm{~m}$ de profundidade por $70 \mathrm{~cm}$ de largura e $50 \mathrm{~m}$ de comprimento. Ao longo desta cava foram identificadas manchas de terra preta com e sem material arqueológico. Barros et al. (2016) descrevem as terras pretas como solos antropogênicos, cuja formação está associada a práticas culturais, estes apresentam estrutura granular, sendo bem drenados, com porosidade total elevada e boa aeração, em geral possuem horizonte A antrópico mais arenoso, podendo variar para texturas mais argilosas, em sítios argilosos, a maior quantidade de microporos favorece a retenção de água e nutrientes. 
Um trabalho de salvamento realizado pela equipe de arqueologia do Museu Paraense Emílio Goeldi (MPEG) resgatou urnas funerárias indígenas, especificamente 12 peças e 2 pingentes líticos que estavam dentro da cava (MACHADO, 1997), caracterizando um amplo cemitério indígena. As urnas já escavadas têm diferentes estilos e decorações, esta variedade de estilos indica que diferentes grupos indígenas utilizaram este cemitério, mostrando que há cerca de mil anos a região da cidade de Macapá já deveria ser um ponto de encontro de culturas.

De modo geral, segundo Pereira (1997), todo o material arqueológico coletado, encontrava-se sob camadas de fragmentos de rochas lateritas, com espessuras variáveis de 3 a $50 \mathrm{~cm}$, de formas arredondadas a alongadas de aspecto "poroso" (Grés do Pará). Sendo que atualmente, há a ocorrência de fragmentos de rochas lateritas, em que foi observada com uma régua de escala de $70 \mathrm{~mm}$. Essa cobertura foi feita pelos indígenas devendo servir como marcador do cemitério e como proteção das urnas funerárias. $\mathrm{O}$ material pedológico apresenta textura areno-argilosa maciça, fortemente friável em condições de umidade moderada, apresentando maior aderência quando saturado. Em condições de semi-umidade, o solo mostra-se resistente, mas aderente.

Esta região é influenciada por um clima equatorial superúmido, isso significa que ocorre uma grande quantidade de calor e umidade, onde a temperatura vária entre $36^{\circ}$ $\mathrm{C}$ a $20^{\circ} \mathrm{C}$. Sendo concordante com o observado em Macapá, onde de acordo com o INMET (Instituto Nacional de Meteorologia), a temperatura média anual é de 26,6 C, com 2561,3 $\mathrm{mm} /$ ano de precipitação e umidade relativa de $83,1 \%$ ao ano; apresentando duas estações distintas: uma chuvosa, predominantemente de dezembro a julho e a menos chuvosa, de agosto a novembro, com os três meses mais secos (setembro, outubro e novembro) agravados pela alta temperatura e baixa umidade relativa (AMANAJÁS et al, 2008).

A Figura 2 apresenta a média mensal da precipitação de Macapá, de 2003 a 2015 (13 anos), demonstrando as duas estações distintas, uma chuvosa, predominantemente de dezembro a julho, com média acima de 270 mm, e a estação menos chuvosa, de agosto a novembro, com média inferior a $44 \mathrm{~mm}$. Setembro, outubro e novembro 
evidenciam os três meses mais secos, com média apenas de 29,4 mm. Na estação mais chuvosas a umidade relativa média mensal é de $80,6 \%$ e na menos chuvosa de $69 \%$, onde Tavares (2014) afirma que nos meses mais secos ocorre um déficit de umidade no solo.

\subsection{Procedimentos de campo}

Para avaliar a influência da precipitação pluviométrica nos dados de resistividade elétrica aparente, foram considerados os dados de precipitação média mensal de 2003 a 2015, obtidos através da Rede de Estações Meteorológicas do INMET de Macapá. Os dados de resistividade elétrica aparente $\left(\rho_{a}\right)$ foram coletados na estação chuvosa, especificamente em abril, e na menos chuvosa, em setembro, juntamente com os dados de precipitação acumulado de 15 dias antes da coleta dos dados geofísicos, para verificar os resultados da resistividade elétrica sazonalmente.

Figura 2 - Média mensal da precipitação (mm) e Umidade Relativa (\%) de Macapá (20032015)

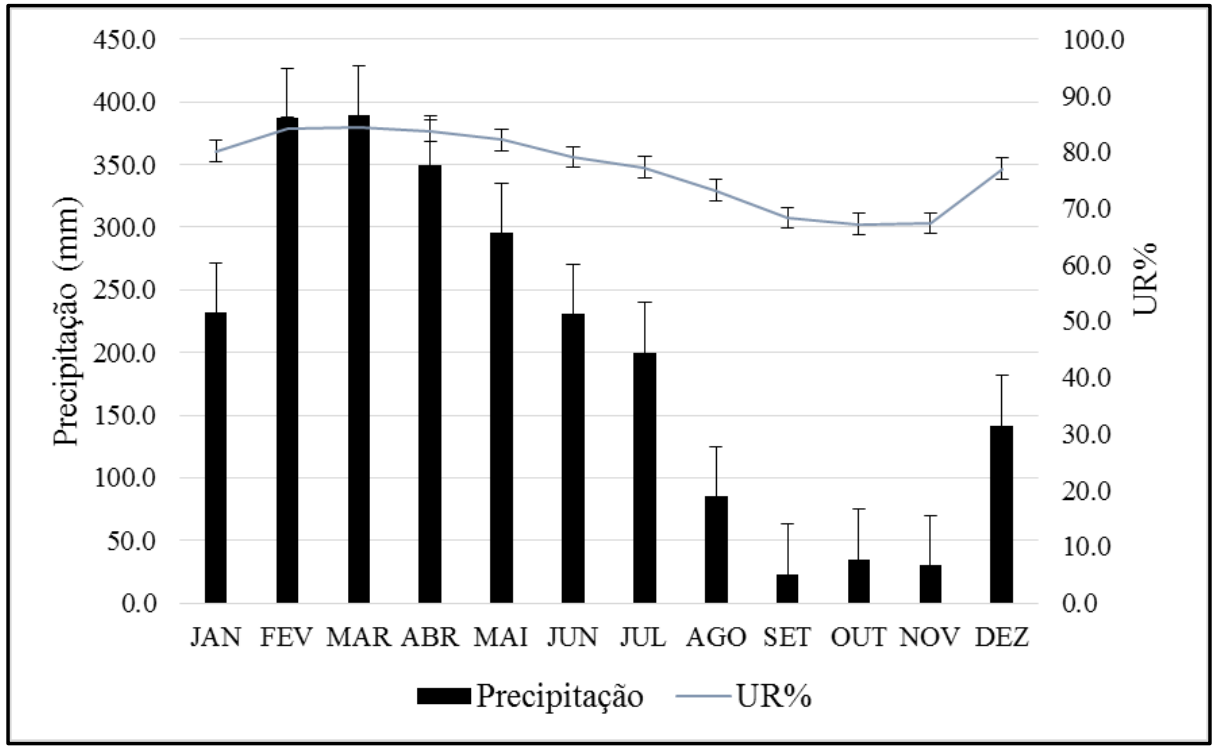

Fonte: Rede de Estações Meteorológicas do INMET de Macapá, elaborado pelos autores

Os dados deste trabalho foram coletados em uma área de $10 \mathrm{~m} \times 20 \mathrm{~m}$ (Figura 3), situada no sítio arqueológico AP-MA-05 (durante o ano de 2015), aplicando o método geofísico de eletrorresistividade, utilizando a técnica do caminhamento elétrico, para verificar a variação lateral de resistividade elétrica do meio. Estes foram adquiridos com 
arranjo dipolo-dipolo, com espaçamento de $1 \mathrm{~m}$ entre os eletrodos, com cinco níveis de amostragem, ao longo de 10 perfis com 20 m de extensão, com espaçamentos entre si de $1 \mathrm{~m}$, segundo a direção EW transversalmente à linha que define a direção em que a cava foi aberta para instalação da rede de drenagem. O equipamento utilizado foi o resistivímetro SARIS, com tempo de injeção utilizado de $1 \mathrm{~s}$. Os dados obtidos pela técnica de caminhamento elétrico foram interpretados da forma qualitativa, usando perfis, mapas e bloco 3D de resistividade elétrica aparente.

Figura 3 - Localização dos perfis de caminhamento elétrico no sítio arqueológico AP-MA05

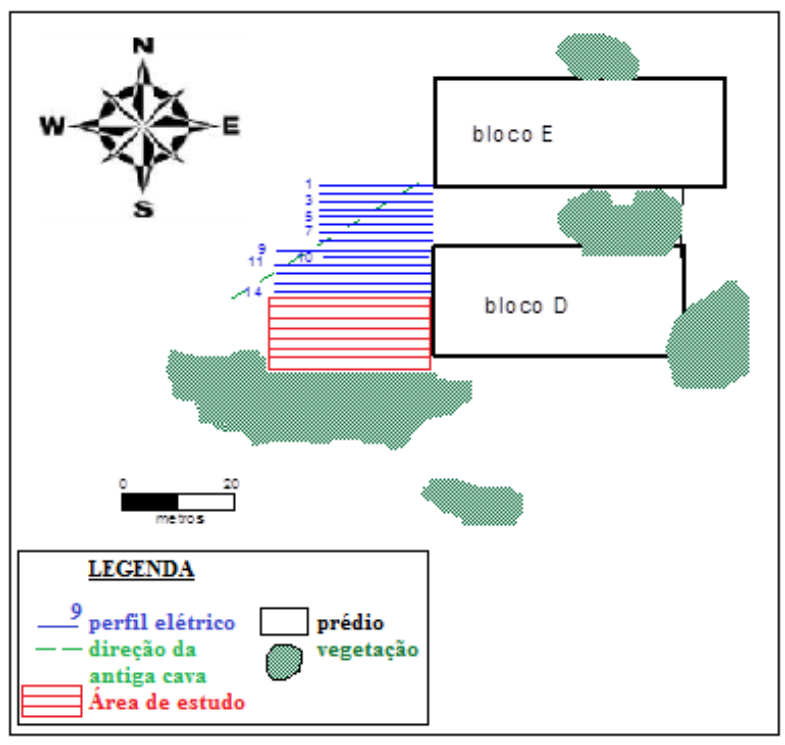

\subsection{Método Geoestatístico}

Para o tratamento dos dados geofísicos foi utilizado prioritariamente o programa R (R Project, 2014), que apresenta vários pacotes geoestatísticos, entre os quais o geo-R e gstat. A metodologia utilizada na geoestatística tem como base os trabalhos de Bortolin e Malagutti Filho (2010), Morais e Bacellar (2010), Leucci e Greco (2012), Vieira (2013) e Seidell e Oliveira (2014), e compreende as seguintes etapas:

- Validação dos dados geofísicos: consiste em verificar a consistência dos dados amostrados em cada Caminhamento Elétrico (CE). Esta verificação não 
abrange somente a consistência das variáveis de interesse, mas também, suas corretas identificações espaciais nas três dimensões.

- Análise Exploratória: após a validação dos dados amostrados pelos métodos de sondagem, a etapa seguinte consiste em obter informações preliminares, principalmente da distribuição das variáveis de interesse, pelas medidas estatísticas clássicas e identificar a possível presença de valores discrepantes (outliers) amostrais. Quando se analisa variáveis é recomendável testar a normalidade das mesmas, pois interferirá na escolha do modelo geoestatístico mais adequado.

- Semivariograma Experimental: nesta etapa são calculados os semivariogramas experimentais para a variável continua ou qualitativa em que se usam variáveis indicadoras para cada categoria. Caso haja indícios de anisotropia, a análise variográfica para diversas direções ajudam na identificação dos ângulos de anisotropia e no alcance dos mesmos.

- Modelagem Variográfica: são baseados em modelos variográficos válidos, que a partir da determinação dos parâmetros, dependem unicamente da distância entre os pontos.

- Determinação dos Suportes para a Modelagem tridimensional (3D: o suporte (o tamanho dos blocos) pode ser escolhido de acordo com especificações obtidas por meio de estudos empíricos, contidos na literatura, ou o menor tamanho computacionalmente factível, pois a expectativa é que: quanto menor os tamanhos dos blocos mais precisos sejam as estimativas das formas na subsuperfície.

- Interpolação e ou simulação: definidos os modelos variográficos de cada categoria e o suporte dos blocos, que é a construção da malha, o passo seguinte é estimar as eletrorresistividades da subsuperfície pela krigagem ordinária ou indicadora por bloco.

- Mapeamento: com os resultados da interpolação ou simulação é possível visualizá-los utilizando mapas iterativos em três dimensões ou várias imagens planas discretizadas em um dos eixos, denominados de slices. Estas funcionalidades estão incorporadas nos pacotes $\mathrm{rg}$ / e lattice, implantados no ambiente $R$, respectivamente. 


\section{RESULTADOS E DISCUSSÃO}

\subsection{Efeito da precipitação pluviométrica}

A precipitação acumulada de 15 dias antes da coleta de abril (2015), mais chuvoso, foi de 143,9 mm, enquanto a precipitação acumulada de 15 dias antes da coleta de setembro, menos chuvoso, foi de $0 \mathrm{~mm}$. Pode-se observar que, em geral, as resistividades no período chuvoso são menores do que as resistividades no período menos chuvoso. Em épocas chuvosas ocorreu um mínimo de 198,7 ohm.m e máximo de 3946 ohm.m, com média total de 1188,9 ohm.m. Em épocas menos chuvosas o mínimo foi de 394 ohm.m, máximo de 5863 ohm.m e média 2078 ohm.m (Figura 4).

A maior variação de resistividade elétrica aparente foi observada no período menos chuvoso. Valores de média e mediana próximos um do outro indicam distribuições com pouca assimetria. Neste caso, a distribuição do período mais chuvoso apresentou-se mais simétrico em relação ao período menos chuvoso. A média representa melhor distribuições simétricas, por isso quanto mais simétrica é a distribuição mais precisas serão as estimativas, uma vez que os métodos de interpolação são, em geral, baseados na média (QUEIROZ, 2003).

Figura 4 - Estatística descritiva e histograma de distribuição da resistividade elétrica aparente.

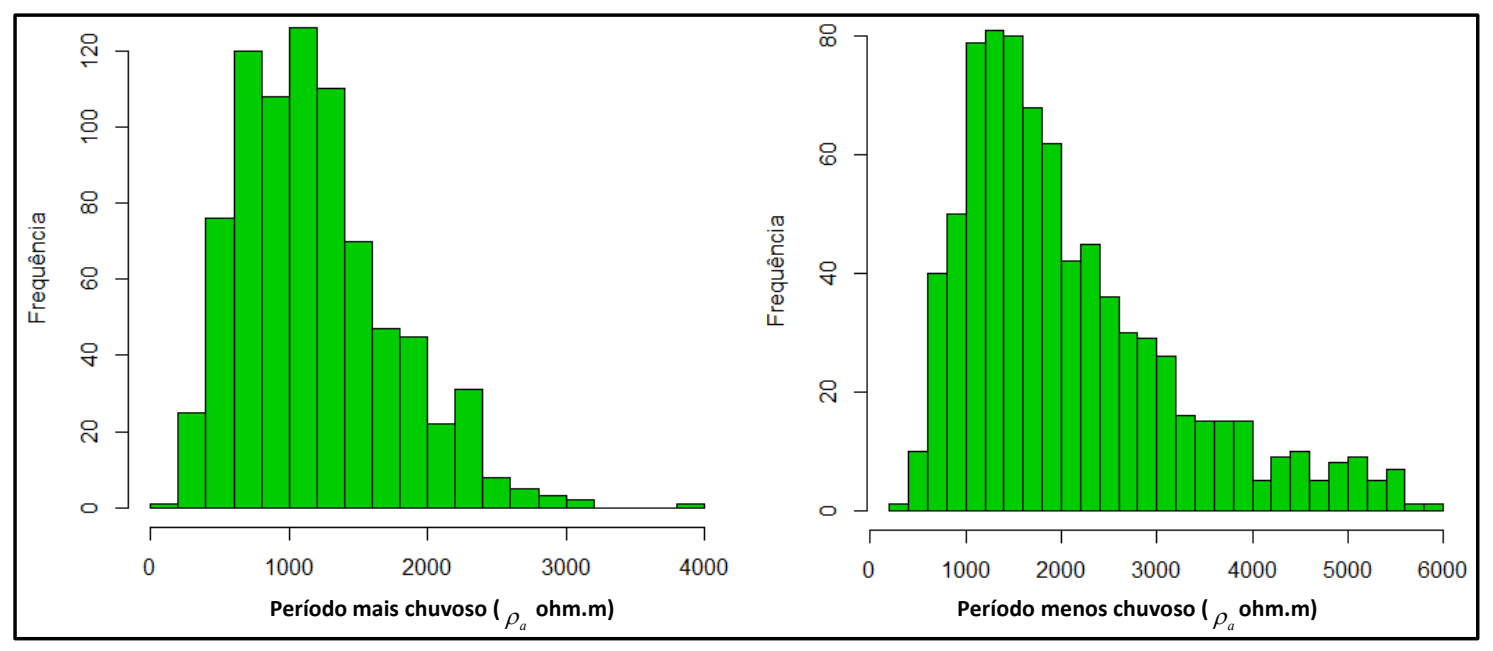




\begin{tabular}{l|c|c}
\hline Estatísticas & Período mais chuvoso $\left(\rho_{a}\right.$ ohm.m) & Período menos chuvoso $\left(\rho_{a}\right.$ ohm.m) \\
\hline Min. & 198,7 & 394,0 \\
\hline Q1 & 764,0 & 1253,0 \\
\hline Mediana & 1115,0 & 1770,0 \\
\hline Média & 1188,9 & 2078,0 \\
\hline Q3 & 1508,2 & 2635,0 \\
\hline Max. & 3946,0 & 5863,0 \\
\hline
\end{tabular}

Para a análise dos dados com o uso da geoestatística foi necessário, inicialmente, realizar o modelamento da variação espacial por meio de variogramas construídos para 10 perfis bidimensionais (2D) obtidos na área de estudo. Foi escolhido um perfil em duas épocas diferentes, chuvosa e menos chuvosa. Em que se observa a ausência de anisotropia nos dois períodos, porém uma forte tendência nos valores medidos de resistividade elétrica aparente, ou seja, na distribuição espacial dos valores as maiores observações situam-se no lado leste da área de estudo. Neste caso, foi feita a opção de se utilizar a krigagem universal, apropriada, nesta situação.

Os modelos espaciais ajustados foram utilizados na krigagem universal para a realização do mapeamento da resistividade elétrica aparente (Figura 5) juntamente com as precipitações nos dois períodos (chuvoso e menos chuvoso). Observa-se claramente a mudança nos valores de resistividade em relação às precipitações. Maiores resistividades parecem estar associadas ao período menos chuvoso enquanto menores resistividades relacionam-se com período mais chuvoso.

Em abril e setembro, épocas em que os dados de resistividade elétrica aparente foram coletados, a média de precipitação pluviométrica em abril, mais chuvoso, foi de 349,5 mm, com resistividade elétrica aparente mínima de 292 ohm.m e valor máximo de 3067 ohm.m, com média de 1272.05 ohm.m. Em setembro, menos chuvoso, a média de precipitação pluviométrica foi de 23,2 mm com valor mínimo de resistividade elétrica aparente de 504 ohm.m e valor máximo de 5450 ohm.m, com média de 2490.8 ohm.m, demonstrando que a precipitação pluviométrica interfere na quantificação dos dados geoelétricos no solo. 
Este resultado é concordante com Cavalcanti (2013) que demonstra a influência da precipitação no delineamento de contaminação de aterros; e Costa e Malagutti Filho (2008) que avaliaram na infiltração de água no solo. A resistividade elétrica aparente é influenciada pela precipitação pluviométrica, visto que quanto mais intensas são as chuvas que ocorrerem na época da obtenção dos dados, menores serão os valores da resistividade elétrica (GANDOLFO; GALLAS, 2005). Além disso, ocorrem os fluxos sub-superficiais que dispersam e transportam massa pelo escoamento da água subterrânea, alterando as concentrações das componentes e equilíbrio geoquímico do solo, especialmente quando o lençol freático está próximo da superfície.

Figura 5 - Média da precipitação mensal (2003-2015) na área de estudo (a); e mapas da krigagem universal para resistividade elétrica aparente do perfil (profundidade em metros) na época chuvosa (b) e na época menos chuvosa (c)
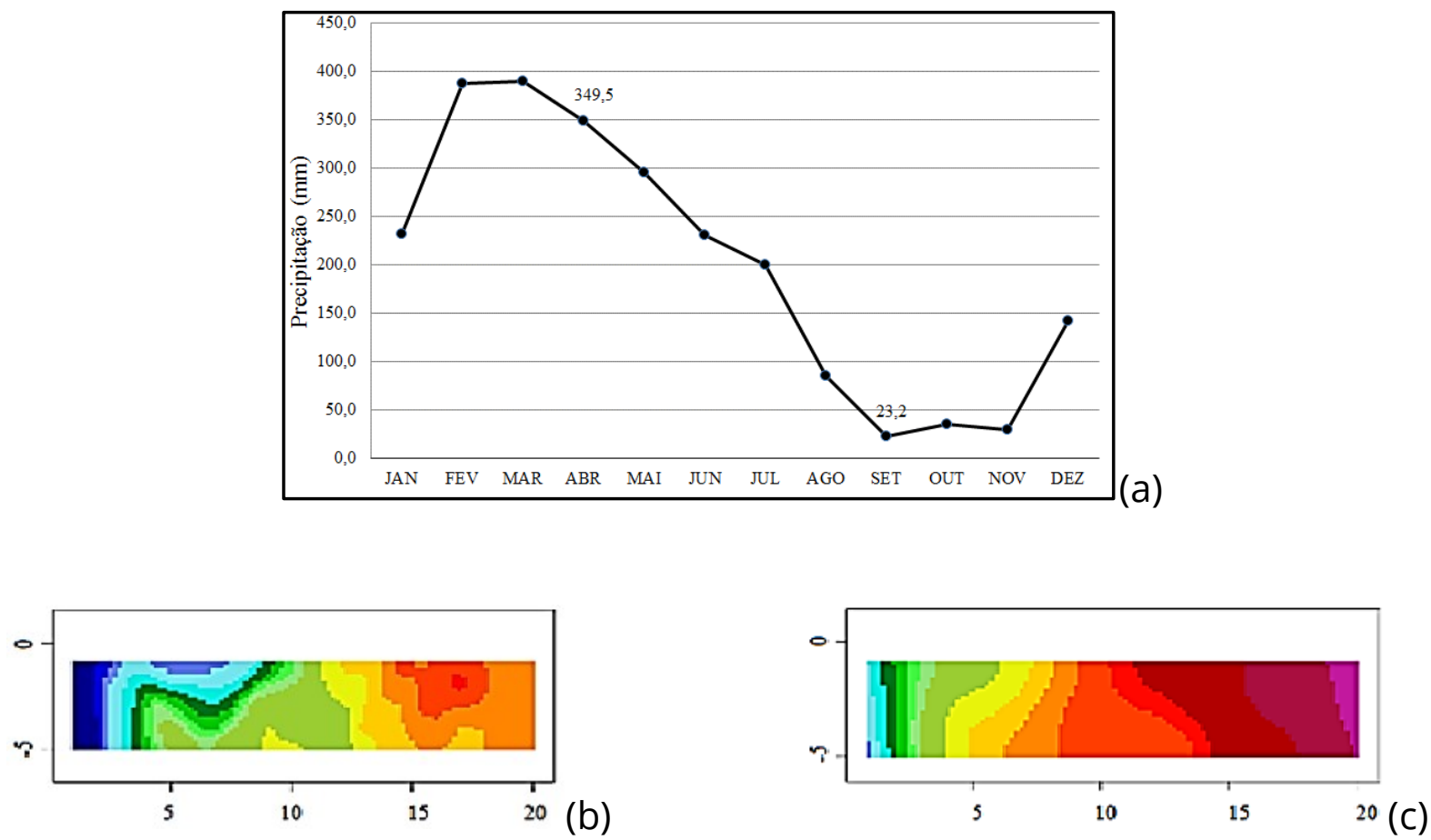

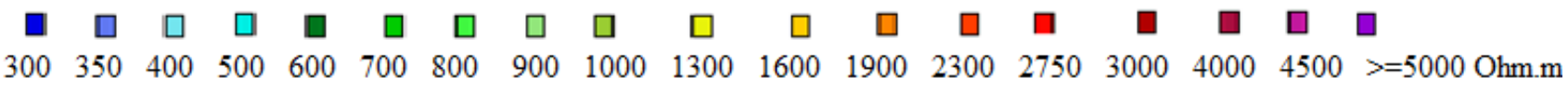




\subsection{Aplicação para investigação arqueológica}

Para a construção do modelo em 3D foram considerados 10 perfis em diferentes níveis de profundidade (Figura 6 a - b). Observa-se que os locais com menor resistividade coincidem com a infraestrutura da UNIFAP onde se localizam os telhados, ou seja, a água que desce neste local torna o terreno mais úmido e, em consequência, menos resistivo. A Figura 6 (c - f) mostra a resistividade elétrica aparente em bloco 3D na subsuperficie do solo arqueológico dentro da UNIFAP, com seus respectivos cortes de secções, para maior investigação na subsuperfície. Observa-se que a época menos chuvosa apresenta maior área com resistividades aparentes mais altas em relação a época chuvosa.

As maiores resistividades ocorrem na parte leste da área de estudo. Entretanto, na parte sudoeste da área observa-se uma anomalia que pode estar relacionada a algum objeto arqueológico, com uma resistividade superior a 2500 ohm.m. Moura (2009) afirma que resistividade predominantemente acima de 2000 ohm.m estão associadas a feições arqueológicas, com a presença fragmentos de rochas lateritas com ou sem vasilhas cerâmicas, compreendendo que intervalo entre os valores de resistividade aparente de 1000 ohm.m a 1500 ohm.m estão associados ao meio natural.

Em relação ao dimensionamento da amostragem, para Gomes e Luiz (2013), na Amazônia deve ser aplicado um método de prospecção intrassítio, especialmente em áreas desmatadas, já que os intervalos de prospecção de superfície costumam ser bem reduzidos; assim a adoção de uma metodologia sistemática de prospecção geofísica possibilita o delineamento de unidades de superfícies contínuas, com uma boa cobertura. 
Figura 6 - Mapa de pontos (seção em metros) da eletrorresistividade (ohm.m) em 3D no período chuvoso (a) e menos chuvoso (b). Bloco 3D para resistividade elétrica aparente na época chuvosa (c), corte de secção na época chuvosa (d), na época menos chuvosa (e) e corte de secção na época menos chuvosa (f). (d) e (f) apresentam cortes para verificação da distribuição em profundidade no perfil
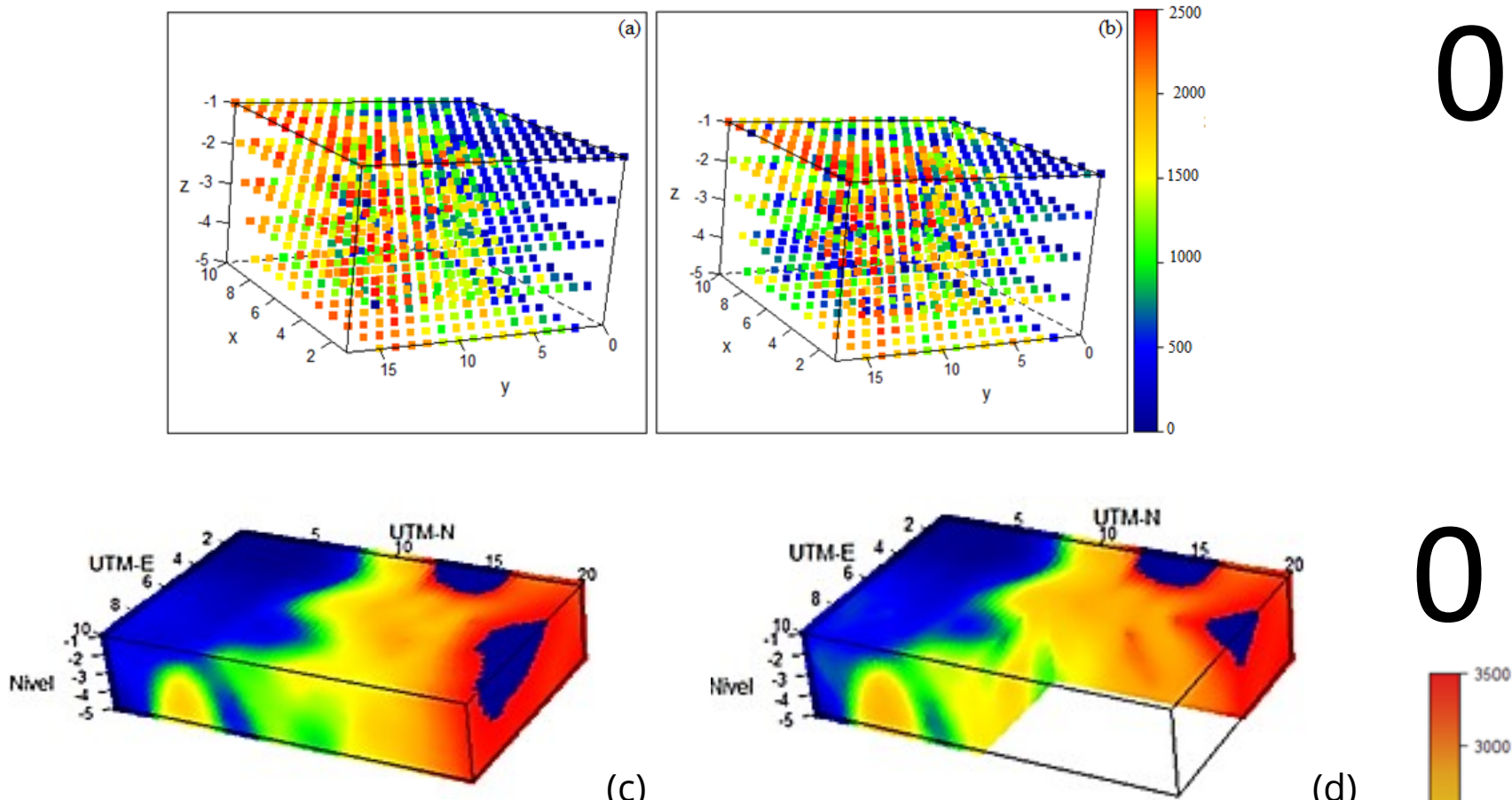

(c)

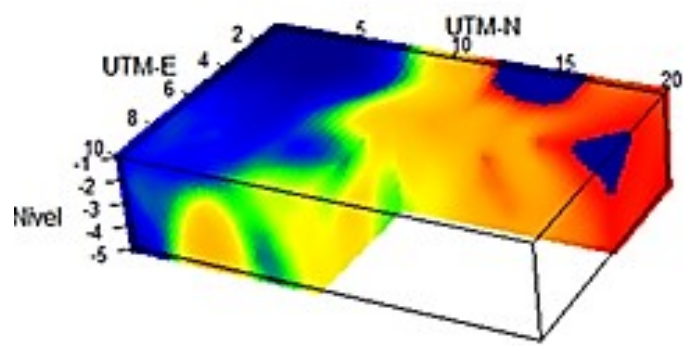

(d)
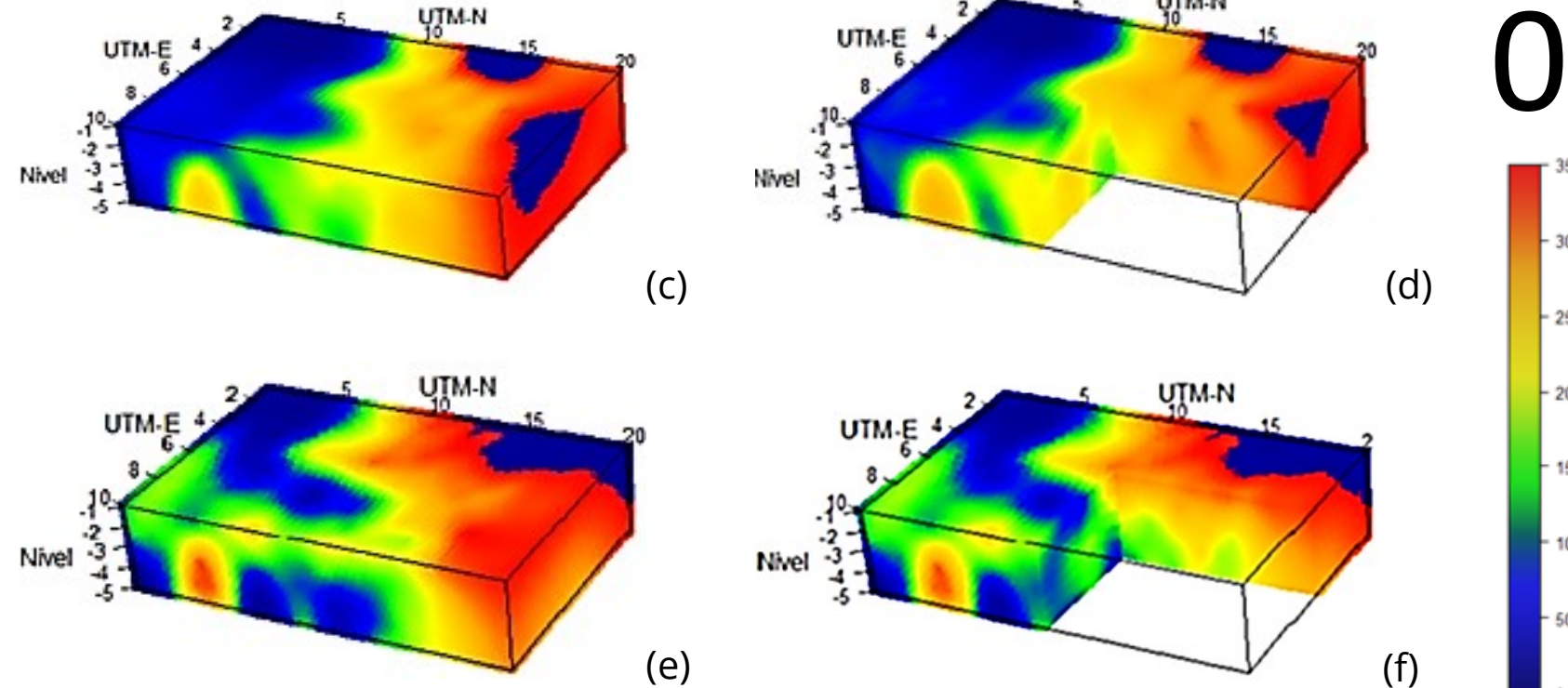

(f)

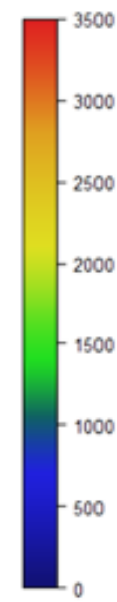

De acordo com Binley et al. (2002), a condutividade elétrica do solo assemelha-se ao comportamento do teor de umidade do solo, pela perda líquida ou ganho de umidade do solo, a partir dos efeitos combinados de precipitação e evapotranspiração. Além de afetar a resistividade do solo, as mudanças sazonais podem influenciar na detecção de características individuais em conjuntos de dados de levantamento de resistividade (FRIEDMAN, 2005; JERVIS; PRINGLE, 2014). As anomalias de resistividades associados a 
alguns sítios arqueológicos são mais fáceis de detectar em época com pouca umidade no solo, em solos relativamente secos (CLARK, 1996).

Para realização de estimativas de volumes em regiões com diversos níveis de resistividade elétrica aparente foi considerada a técnica da krigagem indicativa (Figura 7). Neste caso, foram definidos os quartis para as resistividade em cada período e foram utilizadas variáveis indicadoras para cada quartil. A distribuição foi dividida em 4 partes iguais (os quartis) com $25 \%$ dos valores medidos de resistividade elétrica aparente em cada quartil. Os $25 \%$ dos valores de eletrorresistividade do quartil 1 estavam na faixa de 394 a 1252.75 omh.m. Para os quartis 2, 3 e 4 as variações de resistividade elétrica aparente foram de 1252.75 a 1770.5, 1770.5 a 2635 e 2635 a 5863 ohm.m, respectivamente.

O conjunto integrado dos resultados indica que o mapeamento arqueológico na área do sítio AP-MA-05, utilizando resistividade elétrica aparente teria mais efeito se realizado no período menos chuvoso, onde as anomalias em profundidades dadas pela aderência da umidade no material, teria maior realce.

Figura 7 - Bloco 3D dos quartis no período chuvoso (a) com secção (b) e no período menos chuvoso (c) com secção (d)

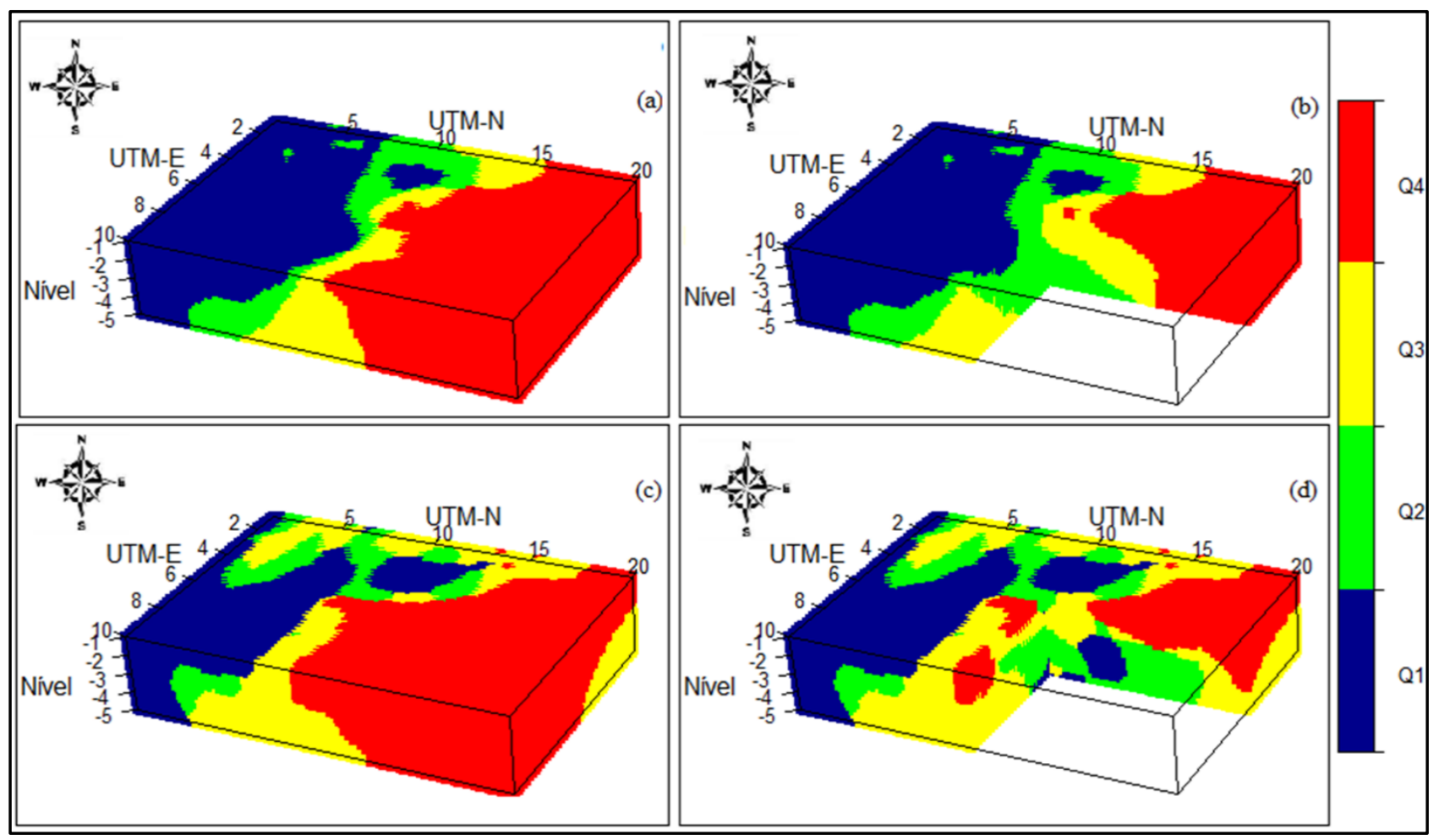


Senna (2016) ao avaliar três sítios arqueológicos (PA-BA-83: Bittencourt, PA-BA84: Alunorte e PA-BA-85: Jambuaçu) do projeto Arqueológico Bauxita Paragominas, no estuário amazônico, concluiu que a prospecção geofísica permite definir zonas anômalas geradas na paisagem a partir das intervenções humanas, porém destaca que as anomalias devem ser testadas por meio de escavações para a correta interpretação dos tipos de anomalia existentes e a elaboração de um painel mais preciso destas.

Meneses e Oliveira (2014) destacam que a instrumentação tecnológica é importante para pesquisa arqueológica, uma vez que possibilita a realização de estudos sem um contato direto com a peça, arte rupestre ou artefato, evitando o risco de desgaste pela manipulação. Para Mojica e Acosta (2008), a aplicação da resistividade elétrica à arqueologia é capaz de gerar modelos com uma boa aproximação das estruturas que estão soterradas. Allen et al. (2017) podem complementar este argumento, por afirmarem que a adoção de métodos geofísicos possibilita o auxílio à localização de alvos de interesse com potencial para as escavações arqueológicas, minimizando o tempo e custos com as escavações, além de atuar como uma estratégia de escavação voltada a preservação.

Aragão et al. (2010) ao pesquisarem os sítios Bittencourt e Jambuaçu (sudoeste da cidade de Belém-Pará) evidenciaram anomalias que tiveram boa aderência quando verificadas via escavação arqueológica, destacando o efeito da profundidade, como observado nos blocos diagramas das Figuras 6 e 7, o que é considerado particularmente importante para a prospecção arqueológica, visto que as fontes anômalas são geralmente rasas e de pequenas dimensões.

E por fim, a integração entre os componentes da paisagem em sítios arqueológicos, conhecendo a climatologia local para melhor escolha do método de prospecção e período de investigação, amplia as possibilidades de sucesso na identificação das ocorrências e melhores resultados durante o processo de escavação. Experiências positivas nesta união são evidenciadas nos trabalhos de Gandolfo e Gallas (2005), Linford (2006), Costa e Malagutti Filho (2008), Ferreira e Menezes (2011), 
Leucci e Greco (2012), Cavalcante (2013), Corrêa et al. (2014), Oliveira et al. (2015) e Senna (2016).

Em se tratando especificamente das condições do sítio tratado, a prefeitura da UNIFAP, responsável de forma geral pela construção de infraestrutura que a universidade necessita, têm a consciência da importância socioambiental da conservação dessa paisagem, com uma maior ciência e consciência sobre a necessidade de um planejamento prévio de obras, com o objetivo de menor desrespeito e violação ao ambiente do sítio, já tendo apresentado para os órgãos competentes um projeto de prospecção para todo o campus, com a sinalização das ações mais adequadas em termos de legislação de preservação de patrimônio a serem tomadas, com a espera, exclusivamente, de recursos. Em relação específica ao sítio arqueológico AP-MA-05 os responsáveis estão com planejamento de prospecção da área do sítio, que se dá com o diagnóstico, prospecção e com o resgate.

\section{CONCLUSÕES}

As medidas de resistividade elétrica aparente observadas no sítio arqueológico APMA-05 apresentaram influência da precipitação pluviométrica, visto que maiores resistividades estão associadas a períodos menos chuvosos, enquanto menores resistividades relacionam-se com períodos mais chuvosos. Assim, em épocas menos chuvosas, os dados coletados são mais promissores. A adoção de métodos geoestatísticos, com o uso de modelos tridimensionais, em associação aos dados geofísicos permitiram melhor visualização e análise da distribuição dos valores estimados no sítio.

O conhecimento do sítio arqueológico AP-MA-05 dentro da universidade fez com que houvesse o aumento da percepção deste em discentes, docentes e responsáveis pela administração direta ou indiretamente da universidade. A valorização do patrimônio cultural é essencial para o desenvolvimento de uma sociedade mais discursiva a respeito de seu papel social, facilitando o debate sobre o crescimento dos espaços urbanos e suas consequências. Estratégias de avaliação de impactos associadas ao desenvolvimento de 
tecnologias, propicia a melhoria das estimativas e a tomada de ações mais proativas, como no caso da UNIFAP, que precisa rever seu plano diretor de expansão de forma a reduzir a pressão em locais de maior sensibilidade natural ou de relevância históricopatrimonial.

\section{AGRADECIMENTOS}

A Coordenação de Aperfeiçoamento de Pessoal de Nível Superior (CAPES) e a Universidade Federal do Amapá (UNIFAP) pelo suporte dado a Pesquisa.

\section{REFERÊNCIAS}

ALLEN SJ, PORSANI JL, POLUHA B. Geofísica arqueológica no ambiente da arqueologia urbana. Revista Arqueologia. 2017;30(1):235-254. https://doi.org/10.24885/sab.v30i1

AMANAJÁS JC, JESUS ES, CUNHA AC, OLIVEIRA LL, FAÇANHAS AT. Avaliação da precipitação pluviométrica observada nos municípios pertencentes à região dos lagos no estado do Amapá. In: Anais do 15 Congresso Brasileiro de Meteorologia [CD-ROM]; 2008, São Paulo, Brasil.

ARAGÃO R, GOUVÊA J, LOPES P. Metodologia geofísica aplicada ao estudo arqueológico dos Sítios Bittencourt e Jambuaçu, Estado do Pará. Revista Brasileira de Geofísica. 2010;28(2):249-263. https://doi.org/10.1590/S0102-261X2010000200009.

BARROS KRM, LIMA HV, RODRIGUES S, KERN DC. Distribuição da porosidade textural e estrutural em solos de Terra Preta Arqueológica. Revista Ciência Agronômica. 2016;47(4):609-615. https://doi.org/10.5935/1806-6690.20160073.

BINLEY A, WINSHIP P, WEST LJ, POKAR M, MIDDLETON R. Seasonal variation of moisture content in unsaturated sandstone inferred from borehole radar and resistivity profiles. J. Hydrol. 2002;267(3):160-172. https://doi.org/10.1016/S0022-1694(02)00147-6

BONNIE R. 'Haven't we dug enough now?' Excavation in the light of intergenerational equity. Archaeological Dialogues. 2011;18(1):48-58. https://doi.org/10.1017/S1380203811000122

BORTOLIN JRM, MALAGUTTI FILHO W. Método da eletrorresistividade aplicado no monitoramento temporal da pluma de contaminação em área de disposição de resíduos sólidos urbanos. Engenharia Sanitária e Ambiental. 2010;15(4):367-374.

https://doi.org/10.1590/S1413-41522010000400009

BRITO-SCHIMMEL P, PORSANI JL, FIGUTI L, DeBLASIS P. Aplicação de métodos geofísicos em Arqueologia: primeiros resultados obtidos no sambaqui fluvial Capelinha, Cajati-SP, Brasil. Rev. 
do Museu de Arqueologia e Etnologia. 2002;12:43-54. https://doi.org/10.11606/issn.24481750.revmae.2002.109437

CAVALCANTI MM. Aplicação de métodos geoelétricos no delineamento da pluma de contaminação nos limites do aterro controlado do Jokey Clube de Brasília - DF [dissertação]. Brasília-DF: Instituto de Geociências; 2013. 111p.

CLARK AJ. Seeing Beneath the Soil: prospecting methods in archaeology. London: Batsford; 1996.

CLUE JK. A new empiricism: excavating at the start of the 21st Century. Archaeological Dialogues. 2011;18(1):30-41. https://doi.org/10.1017/S1380203811000080

COELHO ALN, FERREIRA GAC. Geotecnologias aplicadas em área inundável: o caso de Brejo Grande, Serra-ES. GeoTextos. 2011;7(1):159-183.

http://dx.doi.org/10.9771/1984-5537geo.v7i1.5275

CORRÊA ACB, MUTZENBERG D, SANTOS JÚNIOR V. Arqueologia da paisagem: proposta geoambiental de um modelo para os padrões de assentamentos no enclave arqueológico granito flores, microrregião de Angicos (RN). Revista Clio Arqueológica. 2014;29(2):57-94.

COSTA AF, MALAGUTTI FILHO W. Caracterização estrutural e geofísica da lixeira de Porto Velho (RO). Geociências. 2008; 27(2):229-236.

FAGUNDES M, PIUZANA D. Estudo teórico sobre o uso conceito de paisagem em pesquisas arqueológicas. Revista Latinoamericana de Ciencias Sociales. 2010;8(1):205-220.

FERREIRA RCM, MENEZES CR. Levantamento florístico no sítio arqueológico no campus Marco Zero da UNIFAP. Biota Amazônica. 2011;1(1):74-80.

http://dx.doi.org/10.18561/2179-5746/biotaamazonia.v1n1p74-80

FRIEDMAN SP. Soil properties influencing apparent electrical conductivity: a review. Comput. Electron. Agric. 2005;46: 45-70. https://doi.org/10.1016/j.compag.2004.11.001

FUNARI PP. Arqueologia. São Paulo: Contexto; 2003.

FUNARI PP, NOELLI FS. Pré-história do Brasil. São Paulo: Contexto; 2002.

GANDOLFO OCB, GALLAS JDF. Eletrorresistividade 3D - uma avaliação preliminar da técnica. Revista Brasileira de Geofísica. 2005;23(2):191-198.

https://doi.org/10.1590/S0102-261X2005000200008

GANDOLFO OCB, GALLAS JDF. O arranjo pólo-dipolo como alternativa ao dipolo-dipolo em levantamentos 2D de eletrorresistividade. Revista Brasileira de Geofísica. 2007;25:227-235. https://doi.org/10.1590/S0102-261X2007000300001

HONORATO LC. Arqueologia da paisagem e geoarqueologia: experiências em projetos de pesquisa. Tópos. 2009;3(1):127-147. 
GOMES D, LUIZ J. Contextos domésticos no sítio arqueológico do Porto, Santarém, Brasil, identificados com o auxílio da geofísica por meio do método GPR. Boletim Museu Paraense Emílio Goeldi - Ciências Humanas. 2013;8(3):639-656.

https://doi.org/10.1590/S1981-81222013000300010.

JERVIS JRJ, PRINGLE JK. A study of the effect of seasonal climatic factors on the electrical resistivity response of three experimental graves. Journal of Applied Geophysics. 2014;108:52-60. https://doi.org/10.1016/j.jappgeo.2014.06.008

LEUCCI G, GRECO F. 3D ERT Survey to reconstruct archaeological features in the subsoil of the "Spirito Santo" church ruins at the site of Occhiolà (Sicily, Italy). Archaeology. 2012;1(1):1-6. https://doi.org/10.5923/j.archaeology.20120101.01

LIMA LP. Relatos de uma experiência em Arqueologia Pública. In: Domingues L, Funari PP, Carvalho AV, Rodrigues G. (edts.) Desafios da arqueologia: depoimentos. Erechim: Habilis; 2009. p. 221-223.

LINFORD N. The application of geophysical methods to archaeological prospection. Reports on Progress in Physics. 2006;69(7):2205-2257. https://doi.org/10.1088/0034-4885/69/7/R04/meta

MACHADO ALC. Salvamento arqueológico do sítio AP-MA-5: campus Universitário. Belém-PA: Museu Paraense Emílio Goeldi; 1997.

MENESES FGA, OLIVEIRA LLGS. Estudo prático sobre a geolocalização de sítios arqueológicos no Google Earth. Revista de Arqueologia Pública. 2014;9:35-46.

https://doi.org/10.20396/rap.v8i1.8635664

MOJICA A, ACOSTA L. Prospección geofísica aplicada a la arqueologia: La importancia de los procesos de modelización y simulación numérica. Canto Rodado. 2008;3:17-28.

MORAIS JL. Arqueologia da paisagem como instrumento de gestão no licenciamento ambiental de atividades portuárias. Revista Eletrônica de Gestão de Negócios. 2007;3(4):97-115. https://doi.org/10.18224/hab.v13.1.2015.89-112

MORAIS F, BACELLAR LAP. Geofísica aplicada ao estudo de fluxos da água no solo. Sociedade \& Natureza. 2010;22(1):213-222. https://doi.org/10.1590/S1982-45132010000100015

MOURA HP, SALDANHA JDM, CABRAL MP, OLIVEIRA MJ, CAMARÃO KF, NERY JR. Eletrorresistividade aplicada no sítio arqueológico AP-MA-05, Macapá-AP: resultados preliminares. In: Proceedings of the 11th International Congress of The Brazilian Geophysical Society; 2009 Salvador, Brazil.

OLIVEIRA MJ, BAPTISTA GMM, CARNEIRO CDR, VECCHIA FAS. História geológica e Ciência do clima: Métodos e origens do estudo dos ciclos climáticos na Terra. Terræ. 2015;12(1):03-26.

PEREIRA S. Levantamento plani-altimétrico e fisiográfico para operação de salvamento do sítio arqueológico do Campus Universitário da UNIFAP-Amapá. Amapá: UNIFAP; 1997. 
QUEIROZ JCB. Utilização da geoestatística na quantificação do risco de contaminação por metais pesados, na área portuária de Santana-Amapá [tese]. São Pulo: Universidade Estadual Paulista; 2003. 170p.

R Project. R Development Core Team, 2014, versão 3.2.1. Disponível em https://www.rproject.org/.

SEIDEL EJ, OLIVEIRA MS. Novo índice geoestatístico para a mensuração da dependência espacial. Revista Brasileira de Ciência do Solo, 2014;38(3):699-705. https://doi.org/10.1590/S010006832014000300002

SENNA CSF. Geografia e arqueologia: análise espacial e contextual de sítios arqueológicos no estuário amazônico. Geousp - Espaço e Tempo. 2016;20(2):238-249.

https://doi.org/10.11606/issn.2179-0892.geousp.2016.123728

SILVA JLA, ALMEIDA JAC. Reflexões arqueológicas: estudo dos sítios arqueológicos do município de Queimadas/PB. Revista Eletrônica do Laboratório de Arqueologia e Paleontologia da UEPB. 2011;1(2):112-125.

TAVARES JPN. Características da climatologia de Macapá-AP. Caminhos de Geografia. 2014;15(50):138-151.

VIEIRA TO. Utilização de modelagem geoestatística em 3D na estimação volumétrica de litologias para estudos ambientais [dissertação]. Belém: Universidade Federal do Pará; 2013. $96 p$.

\section{Contribuições de autoria}

\section{1 - Jéssica Lisboa de Albuquerque}

Possui graduação em Engenharia Florestal pela Universidade Federal Rural da Amazônia e mestrado em Ciências Ambientais pela Universidade Federal do Pará.

http://orcid.org/0000-0003-0058-0415 - jessicalisalbuquerque@hotmail.com Contribuição: Concepção, processamento e análise dos dados, escrita, confecção de figuras e tabelas.

\section{2 - Helyelson Paredes Moura}

Possui graduação em Física (Licenciatura) e mestrado em Geofísica, ambos pela Universidade Federal do Pará. Além disso também é doutor em Geociências e Meio Ambiente pela Universidade Estadual Paulista Júlio de Mesquita Filho. Atualmente é professor associado IV da Universidade Federal do Amapá.

http://orcid.org/0000-0001-8639-1687 - helyelson@unifap.br

Contribuição: Desenvolvimento e desenho da metodologia desenvolvida, condução do processo de pesquisa e investigação em campo. 


\section{3 - Joaquim Carlos Barbosa Queiroz}

Possui graduação em Física (Bacharelado) e mestrado em Geofísica, ambos pela Universidade Federal do Pará. Além disso também é doutor em Geociências e Meio Ambiente pela Universidade Estadual Paulista Júlio de Mesquita Filho. Atualmente é Professor Titular do Instituto de Geociências da Universidade Federal do Pará.

http://orcid.org/0000-0002-4459-6956 - joaquim@ufpa.br

Contribuição: Supervisão, condução da proposta metodológica associada à aplicação de técnicas estatísticas, matemáticas e computacionais para analisar e sintetizar os dados de estudo.

\section{4 - Aline Maria Meiguins de Lima}

Possui graduação em Geologia pela Universidade Federal do Pará, especialização em Gestão Normativa de Recursos Hídricos pela Universidade Federal da Paraíba, mestrado em Geotecnia pela Escola de Engenharia de São Carlos da Universidade de São Paulo e doutorado em Desenvolvimento Socioambiental pelo Núcleo de Altos Estudos Amazônicos da Universidade Federal do Pará. Atualmente é Professora da Universidade Federal do Pará.

http://orcid.org/0000-0002-0594-0187 - ameiguins@ufpa.br

Contribuição: Ajuste do trabalho a partir da pesquisa original, especificamente na revisão crítica, formatação de figuras e tabelas, comentários, incluindo a etapa de prépublicação.

\section{Como citar este artigo}

ALBUQUERQUE, J. L.; MOURA, H. P.; QUEIROZ, J. C. B.; LIMA, A. M. M. Influências pluviométricas no mapeamento das características da paisagem de um sítio arqueológico com a aplicação de métodos geofísicos e geoestatísticos. Ciência e Natura, Santa Maria, v. 43, e19, p. 1-22, 2021. Disponível em: https://doi.org/10.5902/2179460X38230. Acesso em: dia, mês (abreviado), ano. 